\title{
The Effect of Vitamin D Supplementation on Skeletal Muscle in the $m d x$ Mouse Model of Duchenne Muscular Dystrophy
}

\author{
Danielle A. Debruin ${ }^{1,2}$, Nicola Andreacchio ${ }^{1}$, Erik D. Hanson ${ }^{1,3}$, Cara A. Timpani ${ }^{1,2}$, \\ Emma Rybalka 1,2 (D) and Alan Hayes 1,2,4,*iD \\ 1 Institute of Sport and Health, Victoria University, Melbourne 3011, Australia; \\ Danielle.debruin@live.vu.edu.au (D.A.D.); nicola.andreacchio@live.vu.edu.au (N.A.); \\ edhanson@email.unc.edu (E.D.H.); cara.timpani@vu.edu.au (C.A.T.); emma.rybalka@vu.edu.au (E.R.) \\ 2 Australian Institute for Musculoskeletal Sciences (AIMSS), Melbourne 3021, Australia \\ 3 Department of Exercise and Sport Science, University of North Carolina at Chapel Hill, Chapel Hill, \\ NC 27599, USA \\ 4 Melbourne Medical School, The University of Melbourne, Melbourne 3010, Australia \\ * Correspondence: alan.hayes@vu.edu.au
}

Received: 29 March 2019; Accepted: 24 April 2019; Published: 26 April 2019

\begin{abstract}
Vitamin D (VitD) has shown to be beneficial in reversing muscle weakness and atrophy associated with VitD deficiency. Duchenne muscular dystrophy is characterized by worsening muscle weakness and muscle atrophy, with VitD deficiency commonly observed. This study aimed to investigate the effect of VitD supplementation on dystrophic skeletal muscle. Eight-week old female control (C57BL/10; $\mathrm{n}=29)$ and dystrophic $(\mathrm{C} 57 \mathrm{BL} / m d x ; \mathrm{n}=23)$ mice were randomly supplemented with one of three VitD enriched diets $(1000,8000 \& 20,000 \mathrm{IU} / \mathrm{kg}$ chow). Following a four-week feeding period, the extensor digitorum longus (EDL) and soleus muscles contractile and fatigue properties were tested ex vivo, followed by histological analysis. As expected, $m d x$ muscles displayed higher mass yet lower specific forces and a rightward shift in their force frequency relationship consistent with dystrophic pathology. There was a trend for $m d x$ muscle mass to be larger following the $20,000 \mathrm{IU} / \mathrm{kg}$ diet, but this did not result in improved force production. Fiber area in the EDL was larger in $m d x$ compared to controls, and there were higher amounts of damage in both muscles, with VitD supplementation having no effect. Four weeks of VitD supplementation did not appear to have any impact upon dystrophic skeletal muscle pathology at this age.
\end{abstract}

Keywords: 1,25(OH)2D: 1,25-dihydroxyvitamin D; 25(OH)D: 25-hydroxyvitamin D3; DMD: Duchenne Muscular Dystrophy; $m d x$ : Duchenne Muscular Dystrophy Mouse Model; Skeletal muscle

\section{Introduction}

Vitamin D (VitD) is a secosteroid that is essential for the proper functioning of the human body [1-3]. Most well-known for its role in regulating bone mineralization [4], VitD has many regulatory actions. In recent years, a link has been established between VitD and skeletal muscle suggesting that VitD may have beneficial effects on muscle strength, reducing muscle fibre atrophy, aiding in muscle regeneration following damage [5,6] and improving calcium handling [7-9]. These recent discoveries open up the possibility for therapeutic use of VitD in degenerative muscle disorders.

One of the most notable degenerative muscular disorders is Duchenne Muscular Dystrophy (DMD); an X-linked recessive disorder that affects 1 in 3500 live male births [10]. Characterized by progressive muscle weakness and gait disturbances [11], DMD is caused by the absence of the integral cytoskeleton protein dystrophin [12,13]. Diagnosed in early childhood, the disease progresses over 
time and leads to severe degeneration and wastage of skeletal muscle; typically resulting in death by the third decade of life [10]. Despite advances in the management of the disease and increased life expectancy, the irreplaceable loss of functional tissue and replacement with fat and connective tissue still leads to the dependence on a wheelchair for movement within a decade of being diagnosed $[10,11,14]$. The overall low quality of life in these patients highlights the need for new therapies that target muscle strength loss. The cycles of degeneration and incomplete regeneration, which are hallmark features of DMD, include some characteristic features of aging muscle, most specifically relating to loss in muscle strength and atrophy of type II muscle fibers [15]. VitD supplementation proves to be beneficial to muscle function in the elderly who are VitD deficient [16,17], as well as muscle atrophy conditions such as post-menopausal associated sarcopenia and cachexia in prostate cancer patients [18,19]. It is possible that VitD supplementation may have the same beneficial effects on dystrophic muscle as has already been shown in aging and VitD deficiency.

There are many preclinical animal models of DMD, including the most commonly used $m d x$ mouse $[20,21]$. The $m d x$ mouse is genetically homologous to the human condition and as a result, many of the pathophysiological processes involved in the damage/regeneration cycle as seen in the human condition are present. Characteristic features of human DMD that are also present in the $m d x$ mouse model include centralized nuclei (an indicator of muscle regeneration), fiber size variability, muscle fiber atrophy and fiber necrosis and fibrosis [22]. As seen in the human disease, the $m d x$ mouse also demonstrates $\mathrm{Ca}^{2+}$ dysregulation and persistent increased intracellular $\mathrm{Ca}^{2+}$ levels [23-26]. In the $m d x$ mouse, muscle degeneration is not evident until three weeks of age after which time striated muscle undergoes severe degeneration [22,27]. At five weeks, damaged muscle enters a period of rapid regeneration which continues to approximately eight weeks of age, after which the hind-limb muscles of the $m d x$ mice cease moving through cyclic phases of muscle degeneration and regeneration [20,28]. From eight-weeks onwards, the hind limb muscles of the $m d x$ mouse remain in a state of low-grade chronic inflammation, damage and regeneration, and necrosis that persists through to adulthood [29]. Thus, to avoid the peak damage/regeneration period, this study aimed to investigate any beneficial effects on skeletal muscle function in eight-week old $m d x$ mice. It was hypothesised VitD supplementation would have several effects on $m d x$ dystrophic muscle including increased absolute force production, decreased fatigue following repeated muscle stimulation, increased recovery capacity post-fatigue and enhanced muscle regeneration.

\section{Materials and Methods}

\subsection{Animals and Ethics Approval}

Ethics approval was granted for this study from the Victoria University Animal Experimentation Ethics Committee (AEETH 13/007) and all experiments performed in relation to this study abided by the Australian Code of Practice for the Care and Use of Animals for Scientific Purposes. A total of 52 eight-week old female control (C57BL/10; $\mathrm{n}=29)$ and dystrophic (C57BL10/mdx; $\mathrm{n}=23)$ mice were obtained from the Animal Resource Center (ARC, Western Australia). Animals were chosen at this age to avoid the peak damage/regeneration period that occurs from 3-6 weeks of age, thus aligning with a period of slower progression of the disease occurring during a period of animal growth and maturation. Mice were randomly provided one of three chow diets varying in their VitD (cholecalciferol) content (Specialty Feeds, WA, Australia); referred to as low, medium and high. For the purpose of this study, the low diet (containing $1000 \mathrm{IU} / \mathrm{kg}$ chow) served as the control diet, as this is the standard content of VitD found in rodent chow and provides the equivalent of 400-1000 IU VitD per day in humans, which are fairly typical daily supplementation doses. The medium diet contained $8000 \mathrm{IU}$ VitD per kilogram of chow whilst the high diet contained 20,000 IU $/ \mathrm{kg}$. Other than the differing VitD levels, the three diets were identical. Chow was contained within a single hopper in each cage and was made available to mice ad libitum following a three-day acclimatization period. Following a four-week 
feeding period, animals were anesthetized with an intraperitoneal injection of pentobarbitone sodium $(60 \mathrm{mg} / \mathrm{kg})$. Muscle tissue was then extracted and tested for functional and histological analysis.

\subsection{Contractility}

The right hind-limb extensor digitorum longus (EDL) and soleus muscles were excised, tendon-to-tendon and tied to a sensitive force transducer in a custom-built organ bath (Zultek Engineering) filled with Krebs-Henseleit Ringer's solution bubbled with carbogen $\left(5 \% \mathrm{CO}_{2}\right.$ in $\mathrm{O}_{2}$; BOC gases, Melbourne, Australia) maintained at a $\mathrm{pH}$ of 7.4 at $30^{\circ} \mathrm{C}$. Supramaximal square wave pulses ( $0.2 \mathrm{msec}$ duration) were used to stimulate all muscle fibers and the force generated measured. The length at which the muscle was able to produce its greatest force was established and maintained for the duration of the testing protocol. In order to determine maximum absolute force ( $\mathrm{Po}$ ), muscles were stimulated at an increasing range of frequencies $(10,30,50,80,100,120,150$ and $180 \mathrm{~Hz})$ with a pulse train of 350 and $500 \mathrm{msec}$ for the EDL and soleus, respectively, with three-minute recovery between each stimulus to prevent fatigue.

\subsection{Fatigue and Recovery}

Following the determination of absolute force (Po), muscles were fatigued through the delivery of repeated, intermittent stimuli for a total duration of three minutes. The EDL was stimulated at $100 \mathrm{~Hz}$ every four seconds, whilst the soleus was stimulated at $80 \mathrm{~Hz}$ every two seconds in order to achieve a comparable level of fatigue in each of the muscles. Muscles were followed during recovery for $60 \mathrm{~min}$ from fatigue, during which time they were stimulated tetanically at specific intervals $(1,2,5$, $10,15,20,30,45$ and $60 \mathrm{~min}$ ) and the forces generated were recorded. Following the conclusion of the protocol, muscles were removed from their bath and cut free from tendons before being blotted to remove excess fluid from the bath and weighed. The cross-sectional area (CSA) for each muscle was determined using both the optimal length and mass of each muscle, according to the equation by Brooks \& Faulkner [30] with muscle density assumed to be $1.06 \mathrm{~g} / \mathrm{cm}^{3}$ [31]. Specific force (sPo) of each muscle was calculated by Po/CSA.

\subsection{Histological Analysis}

Contralateral EDL and soleus muscles were snap frozen in isopentane cooled in liquid nitrogen, and later cut at $12 \mu \mathrm{m}$ using a cryostat (Leica, CM1950) and maintained at a temperature of $-15^{\circ} \mathrm{C}$ before being mounted on glass slides. Samples were stained for haematoxylin and Eosin (H\&E) and photographed using a monochrome camera (Meta Systems, Cool Cube 1) connected to a microscope (Zeiss Imager.Z2). Sections were photographed at $\times 20$ magnification. For analytical purposes, a further $\times 20$ zoom was applied to three random separate areas using the Meta Systems Client Viewer program and the total number of muscle fibers located within each frame was counted, their area measured and averaged. The number of centrally located nuclei (indicative of regeneration) was then counted and expressed as a percentage of total nuclei, while the percent of the section exhibiting muscle damage (infiltrate and phagoctiyc material) was also analysed.

\subsection{Statistical Analysis}

The data presented is expressed as mean \pm SEM. A two-way analysis of variation (ANOVA) was used to analyze data with diet being the within-group factor and strain the between-group factor. If differences and/or interactions were observed Tukey's post hoc test was employed to identify the location of differences. A $p$ value of 0.05 or less was deemed statistically significant.

\section{Results}

Body weight and muscle characteristics are shown in Table 1. Mdx mice were significantly heavier than their healthy counterparts. Similarly, EDL and soleus muscle mass was significantly higher in 
$m d x$ mice. Interestingly, although there was no significant direct effect of $\mathrm{Vit}$, there did appear to be a higher sensitivity to VitD in the dystrophic muscles. The level of significance increased with each dose of VitD, such that despite no difference in muscle mass to body mass ratio with the control diet, the relative EDL mass was higher in $m d x$ mice with both the medium $(p<0.05)$ and high $(p<0.001)$ diets compared to the control strain (see Table 1). A similar effect was seen in the soleus with the high $\operatorname{diet}(p<0.05)$.

Table 1. Body mass and muscle morphology characteristics.

\begin{tabular}{|c|c|c|c|c|c|c|c|}
\hline \multirow{2}{*}{\multicolumn{2}{|c|}{ Measure }} & \multicolumn{3}{|c|}{ C57BL/10 } & \multicolumn{3}{|c|}{$m d x$} \\
\hline & & $\begin{array}{c}1000 \mathrm{IU} \\
\mathrm{n}=10\end{array}$ & $\begin{array}{c}8000 \mathrm{IU} \\
\mathrm{n}=10\end{array}$ & $\begin{array}{c}20,000 \mathrm{IU} \\
n=9\end{array}$ & $\begin{array}{c}1000 \mathrm{IU} \\
\mathrm{n}=7\end{array}$ & $\begin{array}{c}8000 \mathrm{IU} \\
n=8\end{array}$ & $\begin{array}{c}20,000 \mathrm{IU} \\
\mathrm{n}=8\end{array}$ \\
\hline Bod & Weight (g) & $22.1 \pm 1.3$ & $22.2 \pm 1.6$ & $23.9 \pm 0.97$ & $24.6 \pm 0.5^{\wedge}$ & $25.2 \pm 1.0^{\wedge}$ & $25.5 \pm 1.1^{\wedge}$ \\
\hline \multirow{3}{*}{ EDL } & $\begin{array}{l}\text { Mass } \\
(\mathrm{mg})\end{array}$ & $9.5 \pm 0.6$ & $8.7 \pm 0.4$ & $8.8 \pm 0.3$ & $16.8 \pm 2.2^{\wedge}$ & $17.3 \pm 3.4^{\mu}$ & $23.1 \pm 1.8^{m}$ \\
\hline & EDL:BM (mg/g) & $0.046 \pm 0.002$ & $0.041 \pm 0.002$ & $0.041 \pm 0.002$ & $0.068 \pm 0.009$ & $0.074 \pm 0.015^{\wedge}$ & $0.090 \pm 0.007^{m}$ \\
\hline & $\begin{array}{l}\text { CSA } \\
\left(\mathrm{cm}^{2}\right)\end{array}$ & $0.017 \pm 0.001$ & $0.016 \pm 0.001$ & $0.016 \pm 0.001$ & $0.035 \pm 0.006^{\wedge}$ & $0.038 \pm 0.008^{n}$ & $0.047 \pm 0.004^{m}$ \\
\hline \multirow{3}{*}{ SOLEUS } & $\begin{array}{l}\text { Mass } \\
(\mathrm{mg})\end{array}$ & $8.75 \pm 0.47$ & $7.42 \pm 0.42$ & $7.87 \pm 0.43$ & $14.9 \pm 1.7^{\wedge}$ & $14.8 \pm 1.2^{\varkappa}$ & $15.7 \pm 2.4^{m}$ \\
\hline & $\begin{array}{c}\text { Soleus:BM } \\
\text { (mg/g) }\end{array}$ & $0.041 \pm 0.002$ & $0.035 \pm 0.002$ & $0.038 \pm 0.003$ & $0.061 \pm 0.007$ & $0.059 \pm 0.005$ & $0.072 \pm 0.018$ \\
\hline & $\begin{array}{l}\mathrm{CSA} \\
\left(\mathrm{cm}^{2}\right)\end{array}$ & $0.010 \pm 0.001$ & $0.010 \pm 0.001$ & $0.009 \pm 0.001$ & $0.017 \pm 0.002{ }^{\wedge}$ & $0.021 \pm 0.002^{m}$ & $0.018 \pm 0.002^{\varkappa}$ \\
\hline
\end{tabular}

Abbreviatons: $\mathrm{EDL}=$ extensor digitorum longus; $\mathrm{BM}=$ body mass; $\mathrm{CSA}=$ cross sectional area. Symbols indicate: ${ }^{\wedge} p<0.05, \wedge p<0.01, \wedge$ ^ $p<0.001$; Significantly different from C57 strain.

Despite this apparent effect, there was no translation into improved function of dystrophic muscles. As expected, $m d x$ EDL muscles had both lower absolute and specific forces than their control strain counterparts (see Figure 1), due to preferential loss of fast-twitch fibers in dystrophic pathology. While soleus (slow-twitch) muscles had similar absolute forces, their larger size meant that specific forces was also lower in $m d x$ mice compared to controls (see Figure 1). As mentioned, VitD had minimal effect on force production in either muscle, with higher specific forces $(p<0.05)$ in the soleus muscle with the high diet compared to low, but only in the control strain.

Force-frequency relationships demonstrated significant rightward shifts $(p<0.001)$ in the $m d x$ mice in both the EDL and soleus muscles compared to the control strain (see Figure 2). VitD supplementation again had no significant effects, although there was a trend for higher forces at lower frequencies after the high diet in the EDL muscle.

Despite no effect of VitD on force development, it appeared that medium and high doses of VitD improved fatigue in the EDL of the healthy animals $(p<0.05$, Figure 3A). Furthermore, there was a strong tendency $(p<0.1)$ in the healthy high dose EDL muscles to be higher than the healthy low VitD supplemented during recovery (see Figure 3). Conversely, no direct effect of VitD was found on fatigability or recovery in the $m d x$ EDL muscles - only strain differences were observed during the later stages of recovery between the medium diet groups ( $p<0.05$, Figure 3B). Interestingly, no strain differences were observed in the soleus muscles during the fatigue and recovery protocols, with only the healthy medium diet animals displaying lower rates of recovery at 15 and $30 \mathrm{~min}$ when compared to the high group $(p<0.05$, Figure $3 C$ ). There was also a strong tendency for the high dose non-dystrophic muscles to have a higher recovery capacity than the medium group at 20 and $45 \min (p<0.08$ and $p<0.06$, respectively). However, no such effects were observed in the soleus muscles of $m d x$ mice. 
A

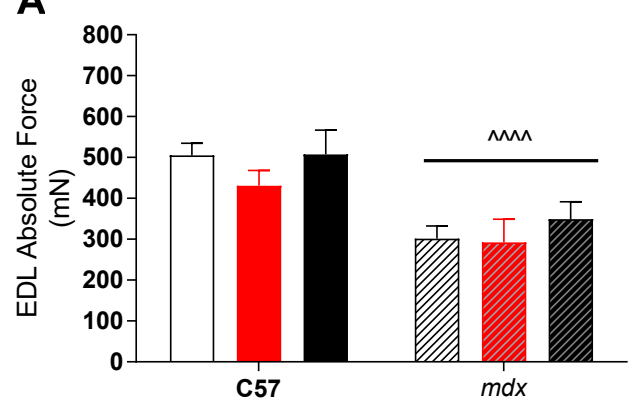

C

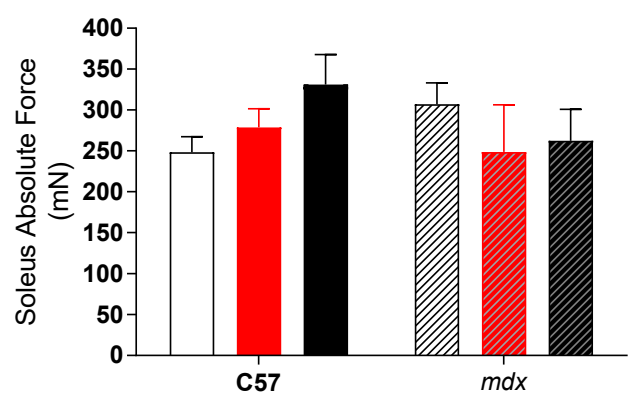

B

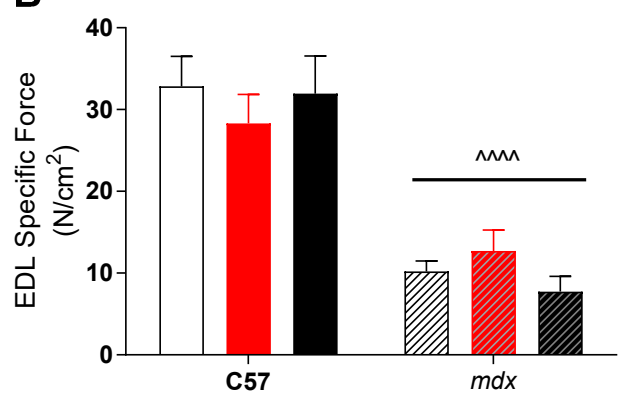

D

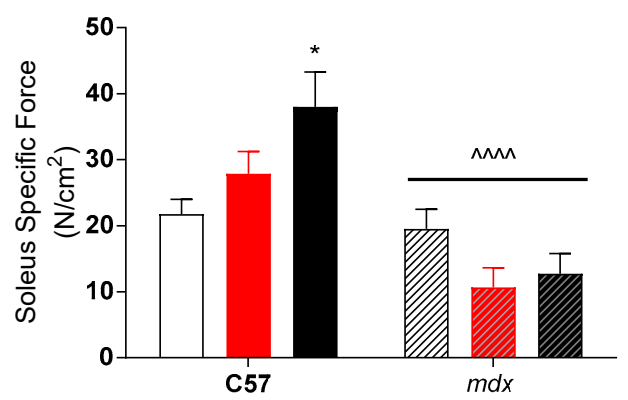

Figure 1. Extensor digitorum longus (EDL) and soleus (SOL) absolute and specific force production in non-dystrophic and $m d x$ animals. Absolute tetanic force (A) and specific force $(\mathbf{B})$ of the EDL muscle from C57 and $m d x$ mice from low (open bar; $\mathrm{n}=4-10$ ), medium (red bar, $\mathrm{n}=6-10$ ) and high (black bar; $\mathrm{n}=6-10)$ vitamin D enriched diets. SOL absolute (C) and specific force (D) from C57 and $m d x$ mice from low (open bar; $\mathrm{n}=6-10$ ), medium (red bar, $\mathrm{n}=6-10$ ) and high (black bar; $\mathrm{n}=6-10$ ) vitamin $\mathrm{D}$ enriched diets. Symbols indicate: ${ }^{*} p<0.05$, significantly different to low diet. ${ }^{m \wedge} p<0.0001$, significantly different to C57 strain.

A

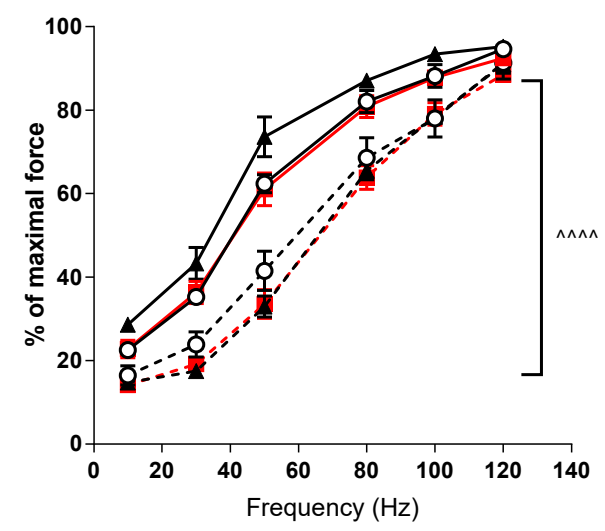

B

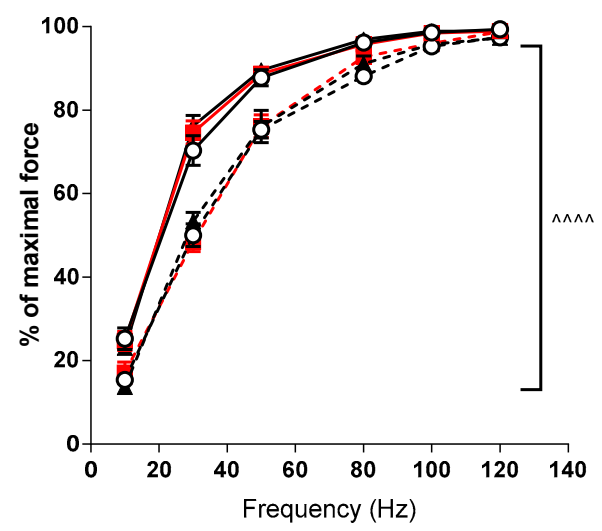

Figure 2. EDL and soleus (SOL) force frequency relationship in non-dystrophic and $m d x$ animals. EDL muscles (A) from C57 mice fed low $(\mathrm{O} ; \mathrm{n}=5)$, medium $(\boldsymbol{\square} ; \mathrm{n}=4)$ and high $(\mathbf{\Delta} ; \mathrm{n}=6)$ vitamin $\mathrm{D}$ enriched diets and $m d x$ mice fed low $(\mathrm{O}$, broken line; $\mathrm{n}=6)$, medium $(\boldsymbol{\square}$, broken line; $\mathrm{n}=6)$ and high $(\mathbf{\Lambda}$, broken line; $\mathrm{n}=5)$ vitamin D enriched diets. SOL muscles $(\mathbf{B})$ from C57 mice fed low $(\mathrm{O} ; \mathrm{n}=5)$, medium $(\square ; \mathrm{n}=4)$ and high $(\boldsymbol{\Lambda} ; \mathrm{n}=6)$ vitamin $\mathrm{D}$ enriched diets and $m d x$ mice fed low $(\mathrm{O}$, broken line; $\mathrm{n}=6)$, medium $(\boldsymbol{\square}$, broken line; $\mathrm{n}=6)$ and high $(\mathbf{\Lambda}$, broken line; $\mathrm{n}=5)$ vitamin $\mathrm{D}$ enriched diets. Symbols indicate: ${ }^{\wedge \wedge} p<0.0001$ significant difference between $\mathrm{C} 57$ and $m d x$ strains. 
A

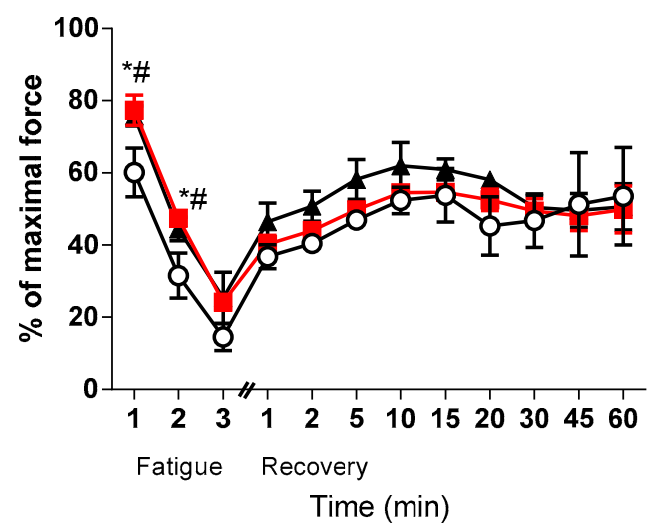

C

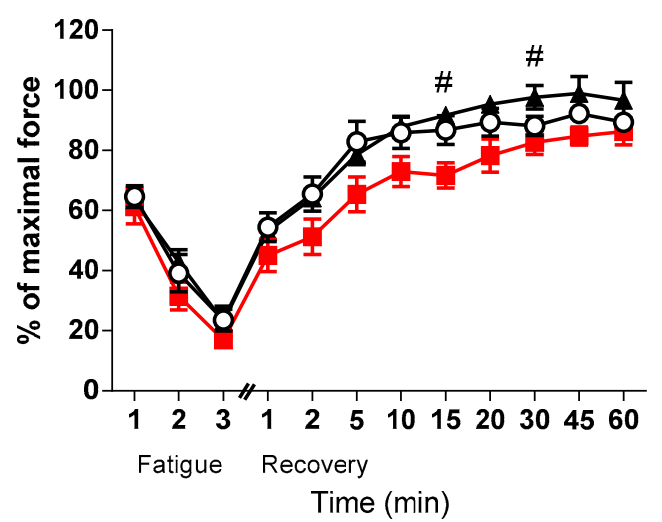

B

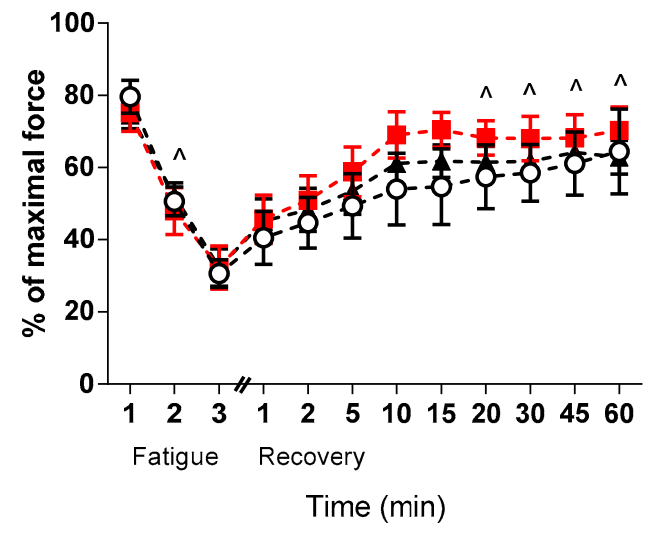

D

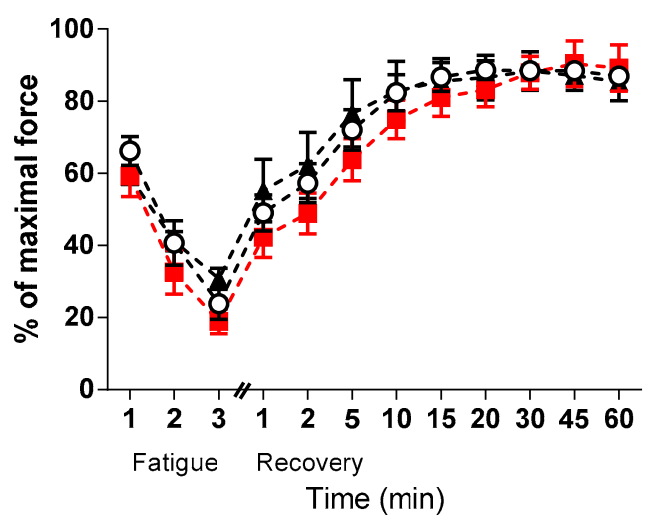

Figure 3. EDL and soleus (SOL) Fatigue and Recovery in non-dystrophic and $m d x$ animals. Fatigue and Recovery of (A) EDL muscles from C57 mice from low $(\mathrm{O} ; \mathrm{n}=5)$, medium $(\boldsymbol{\square} ; \mathrm{n}=4)$ and high $(\mathbf{\Delta}$; $\mathrm{n}=6$ ) vitamin $\mathrm{D}$ enriched diets. (B) EDL muscles from $m d x$ mice from the low $(\mathrm{O}$, broken line; $\mathrm{n}=6)$, medium ( $\square$, broken line; $\mathrm{n}=6)$ and high $(\boldsymbol{\Lambda}$, broken line; $\mathrm{n}=5)$ vitamin D enriched diets. (C) SOL muscles from C57 mice from low $(\mathrm{O} ; \mathrm{n}=5)$, medium $(\square ; \mathrm{n}=4)$ and high $(\mathbf{\Lambda} ; \mathrm{n}=6)$ vitamin $\mathrm{D}$ enriched diets and (D) SOL muscles from $m d x$ mice from the low $(\mathrm{O}$, broken line; $\mathrm{n}=6)$, medium $(\boldsymbol{\square}$, broken line; $\mathrm{n}=6)$ and high $(\boldsymbol{\Lambda}$, broken line; $\mathrm{n}=5)$ vitamin $\mathrm{D}$ enriched diets. Symbols indicate: ${ }^{*} p<0.05$, significantly different from low diet). \# $p<0.05$, significantly different from the medium diet. ${ }^{\wedge} p<0.05$, significantly different from the C57 strain.

Analysis of fiber size distribution in EDL muscles stained with H\&E found that there was no significant effect of VitD in either the non-dystrophic or $m d x$ mice (see Figure $4 \mathrm{~A}$ ). As expected, there was increased variation in frequency of fibre distributions in both EDL and soleus muscles of $m d x$ mice (see Figures 4 and 5), reflective of damage, regeneration and pseudohypertrophy found across all VitD diets $(p<0.0001$; Figure 4D). Interestingly, CSA was unaffected in the slow-twitch soleus muscle with the strain and VitD having no impact. Analysis of control muscle sections found there were no central nuclei located in samples, thus regenerative capacity was analysed only in the $m d x$ muscle samples. As expected, both EDL and soleus $m d x$ muscles demonstrated high proportions of regenerating fibres $(\sim 30-40 \%$ ), and this was unaffected by VitD (Figures $4 \mathrm{E}$ and $5 \mathrm{E}$ ). Phagocytic infiltration of muscle was evident in both EDL and soleus $m d x$ muscle samples. These areas depict phagocytic cells converged at various sites of muscle damage and were analysed as a percentage of total area (Figures 4F and 5F). Again, there were no differences with VitD supplementation. 
A

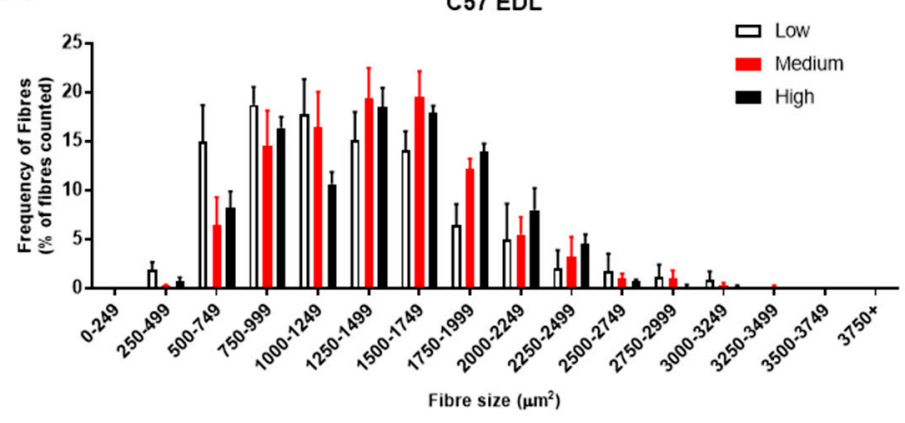

B

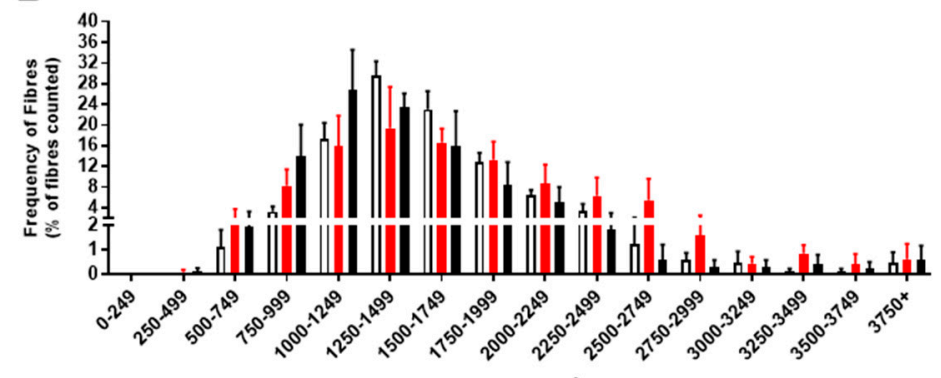

Fibre size $\left(\mu \mathrm{m}^{2}\right)$
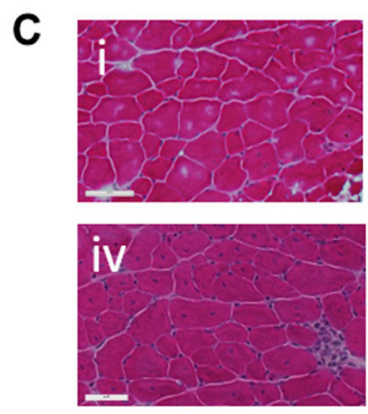
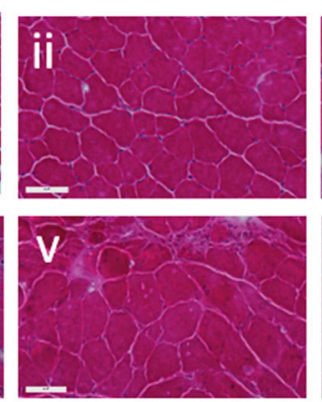
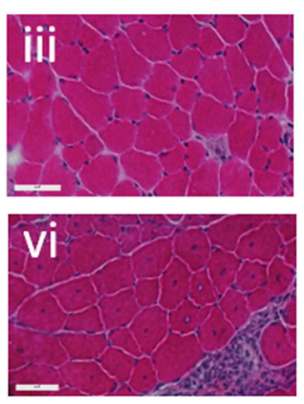

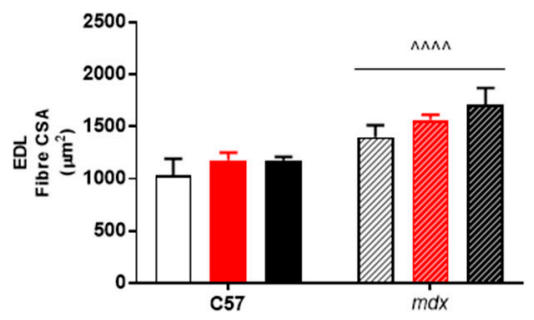

E
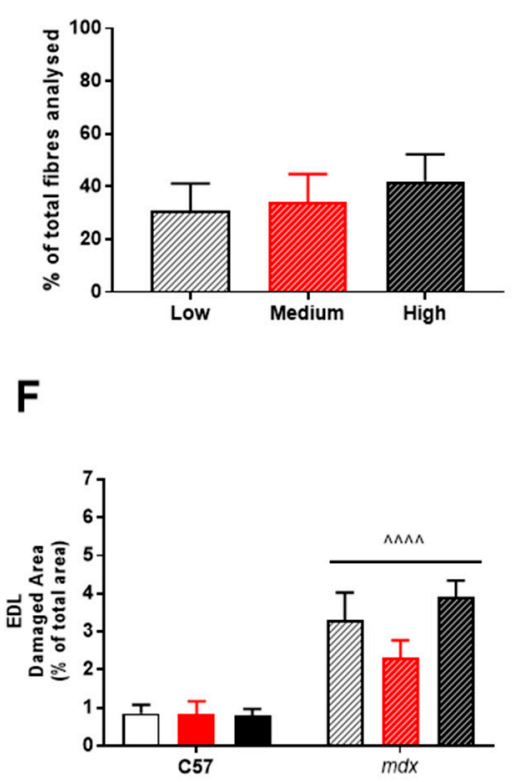

Figure 4. Histological analysis of the EDL in non-dystrophic and $m d x$ animals. Fibre size distribution in non-dystrophic (A) and $m d x(\mathbf{B})$ animals treated with low (white bar), medium (red bar) and high (black bar) vitamin D enriched diets. Representative images are depicted in panel (C); low, medium and high vitamin D diets (C57 i-iii and $m d x$ iv-vi, respectively). Fibre cross-sectional area (D), percentage of regeneration (E); $m d x$ only) and damage (F) was also analysed in non-dystrophic $\mathrm{C} 57$ and $m d x$ mice fed low, medium and high amounts of vitamin D. Symbols indicate: ${ }^{\wedge \wedge} p<0.0001$, significantly different to $\mathrm{C} 57$ strain. All groups $n=4$. Scale bar $=50 \mu \mathrm{m}$. 
A

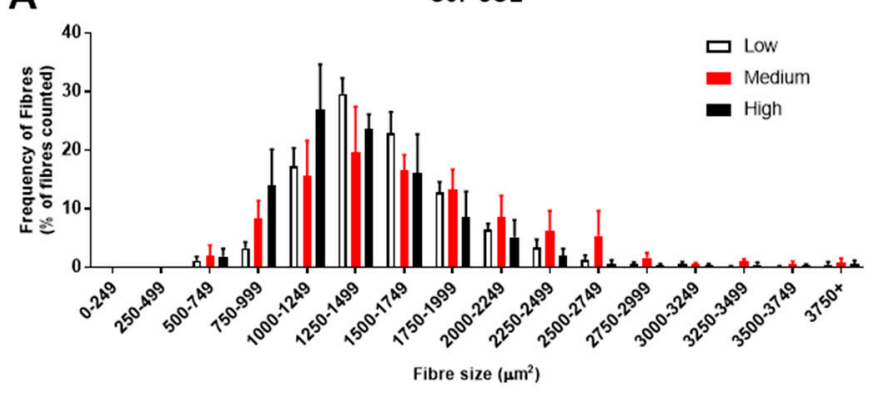

B

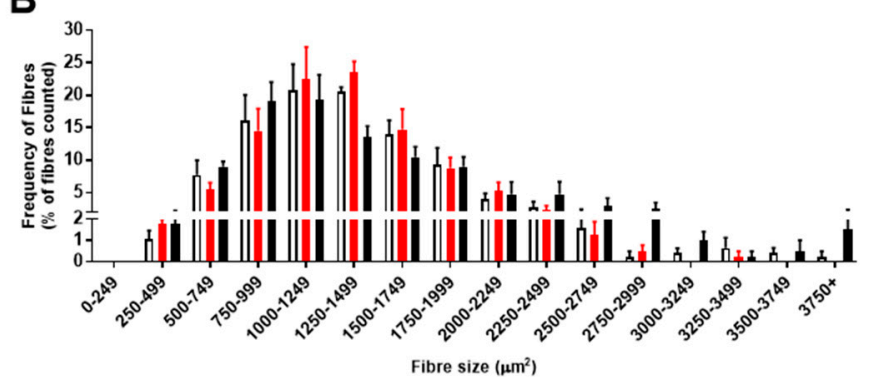

C
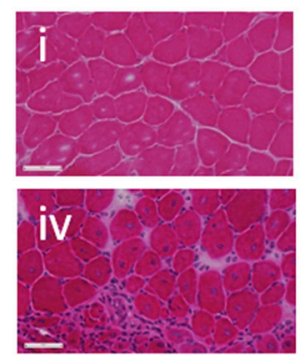
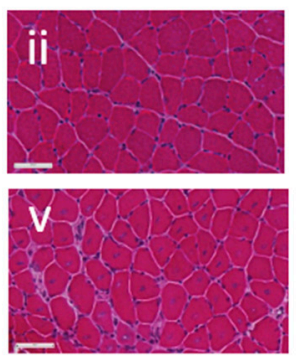
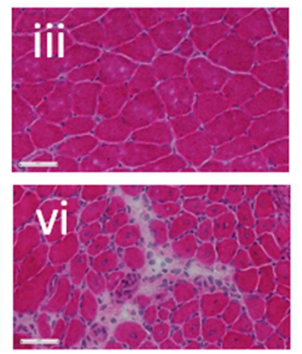

D

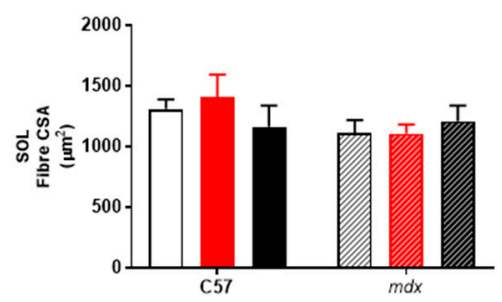

E

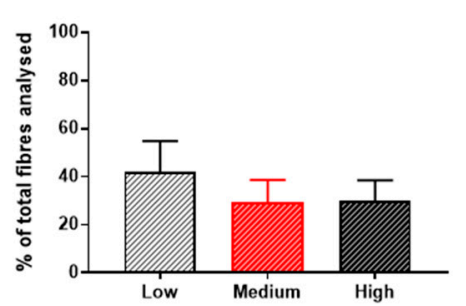

$\mathbf{F}$

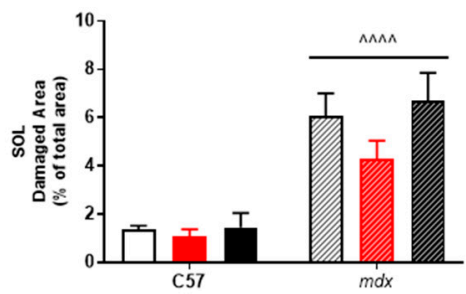

Figure 5. Histological analysis of the soleus (SOL) in non-dystrophic and $m d x$ mice. Fiber size distribution in non-dystrophic (A) and $\mathrm{mdx}(\mathbf{B})$ animals treated with low (white bar), medium (orange bar) and high (black bar) vitamin D enriched diets. Representative images are depicted in panel (C); low, medium and high vitamin D diets (C57 i-iii and $m d x$ iv-vi, respectively). Fibre cross-sectional area (CSA; (D)), percentage of regeneration ( $m d x$ only; $(\mathbf{E}))$ and damage $(\mathbf{F})$ was also analysed in non-dystrophic C57 and $m d x$ mice fed low, medium and high amounts of vitamin D. Symbols indicate: $\wedge^{\wedge} p<0.0001$, significantly different to C57 strain. All groups $\mathrm{n}=4$. Scale bar $=50 \mu \mathrm{m}$.

\section{Discussion}

The major finding of the current study was that VitD supplementation did not appear to have a significant impact on either contractility or regeneration in $m d x$ mouse muscles. Impaired muscle function in the $m d x$ mouse was as expected, with deficits in force production and calcium handling, which was accompanied by instances of muscle fiber damage and regeneration. Indeed, force production of dystrophic muscle is increasingly affected as the number of degenerating muscle fibers and regenerating myotubes increases over time as result of the genetic-mutation that leads to the loss of the protein dystrophin [32-35], resulting in lower specific forces in dystrophic muscles.

In the human form of the disease, boys with DMD lose the ability to ambulate during the teenage years as muscle damage and loss of functional tissue leads to an inability to generate appropriate amounts of force. In this present study, 12-week old EDL and soleus muscles from $m d x$ animals had significantly lower specific forces than the controls regardless of diet (see Figure 1). Moreover, the clear impact of the dystrophic condition on type-II fibers are illustrated in the EDL of $m d x$ mice, which produce significantly less absolute force than healthy controls despite an increase in the size of their muscles, something which is commonly seen in dystrophic fast-twitch muscles [36], resulting in lower specific force. Whilst muscle fibers are damaged and lost, it is believed that surrounding 
fibers compensate for this and hypertrophy [15] and is indicated by an increase in muscle mass size relative to non-dystrophic controls (see Table 1). However, while this maintains force in slow-twitch muscles such as the soleus, the amount of regenerated and non-contractile material also results in lower specific force.

The presence of a rightward shift in the force-frequency relationship can indicate a shift to a faster phenotype, as higher frequencies of activation are required for summation. However, lower forces and preferential loss of fast-twitch fibers in dystrophic muscles [37-39] make that explanation unlikely. As such, lower forces displayed by the $m d x$ mice suggest changes in $\mathrm{Ca}^{2+}$ sensitivity, as a higher frequency (to elicit sufficient calcium release) is required to produce maximal force. While altered calcium dynamics have been well reported in dystrophic muscle [40-42], there does not appear to be any effect of VitD on the force frequency relationship, although further studies with single muscle fibers are required to fully elucidate this.

As well as no effect on the force frequency (and thus calcium handling), there was also no effect of VitD on muscle mass or force, although there was some suggestion of heightened sensitivity to VitD in the dystrophic muscles. This was despite previous research demonstrating that VitD may aid muscle recovery and improve muscle strength [5-7]. Further, there were also limited effects on fatigue and recovery with VitD supplementation. The lack of VitD effect in the dystrophic EDL muscles may be due to the gradual increase in the proportion of fatigue-resistant slow-twitch fibers [43,44]. It may be that effects of VitD are masked by the higher fatigue resistance offered by slow-twitch muscle fibres. Indeed, the $m d x$ EDL did not fatigue to the same level as control EDL muscles after two minutes and then again at multiple points during recovery (see Figure 3). In support of this, beneficial effects of VitD were not observed in the non-dystrophic soleus muscles suggesting that effects are only provided to fast-twitch fibers. Since there is preferential loss of fast-twitch fibers in dystrophic EDL muscles, this may explain why effects are only seen in the non-dystrophic animals, and suggests that any VitD therapy would need to be started prior to significant fast-twitch fiber loss.

The data from this study does not support the use of VitD supplementation as it did not lead to increased muscle force output or return dystrophic EDL or soleus muscle forces to control levels. However, there were a number of limitations to the study. VitD may be most effective during periods of damage and repair [5]. The current study deliberately avoided the peak damage and repair period as this is well above what is observed in human dystrophy. As a result, the study was during a period of lower levels of muscle degeneration and regeneration. As such, there may have been insufficient stimulus for VitD to have any major effect, or insufficient fast-twitch fibres for any effect to be realised. Whilst muscle degeneration can be equally matched with regeneration for a sustained amount of time in the $m d x$ mouse, degeneration slows considerably, and only low-grade chronic inflammation persists [29]. Thus, it is possible that in this study, the damage-regeneration phase from 8- to 12-weeks is not severe enough for VitD to take effect. Alternately, if VitD were decreasing the number of degenerating muscle fibers, whilst also increasing the rate of regeneration, as suggested by $[5,45]$ then the overall outcome in centralised nuclei could be the same and may conceal any effects of VitD. It is reasonable to suggest that future studies should consider timing of supplementation and apply it during the peak damage period between 14-28 days old. This is even more pronounced when it is considered that VitD supplementation has been shown to be most effective in those deficient in VitD. While DMD sufferers are more likely to be VitD deficient, the current study investigated mice that would have had usual levels of VitD, as they were on the typical (1000 IU/kg chow) diet until the study began at 8 weeks of age. Thus, it is possible that the lack of effect in the dystrophic animals may be due to the animals beginning supplementation with normal levels of VitD. If the $m d x$ mice were deficient prior to VitD feeding, the severity of the dystrophic phenotype would likely increase, thus enabling VitD to have a more significant effect. Indeed, studies have demonstrated that VitD deficient non-dystrophic mice are weaker than sufficient controls and is effectively reversed with VitD supplementation [7]. 
Despite no direct impact of VitD on muscle function in the $m d x$ mouse, it appeared to have improved force production in the soleus and fatigue resistance in the EDL in normal muscles. The ergogenic potential of VitD to increase muscle performance has been discussed previously [46]. The studies outlined demonstrated a positive link between VitD status and various aspects of muscle function that athletes require for optimal performance. For example, it has been found in numerous studies that serum $25(\mathrm{OH}) \mathrm{D}$ levels are positively correlated with muscle force, power, velocity and jump height [47-50]. In addition to this, a study investigated whether serum VitD levels could influence the recovery rates of muscle strength after resistance training-induced muscle damage [51]. It was found that pre-exercise VitD serum levels predicted the level of recovery of muscle strength after an acute bout of resistance exercise. Specifically, the higher the level of circulating VitD in the blood [25(OH)D] prior to exercise, the lower the post-exercise muscle weakness. By improving the recovery time from intense exercise, this would potentially allow athletes to train more intensely and/or more frequently, which is likely to increase exercise performance over a long period of time.

Increased recovery rates would also benefit aerobic exercise performance, with a link between aerobic athletic performance and VitD status in humans made via correlative studies [52,53]. A positive correlation between VitD status and $\mathrm{VO}_{2}$ max (the gold standard indicator of aerobic cardiorespiratory fitness) [54] suggest that subjects with a high VitD status have increased aerobic capacity and, thus, that VitD supplementation may potentiate exercise abilities. However, most VitD supplementation studies have been conducted on VitD deficient or insufficient athletes, in which the greatest improvements in muscle strength, power and speed are seen compared to their control counterparts with normal endogenous VitD levels ( $>50 \mathrm{nmol} / \mathrm{L}$ ) [48-50]. Furthermore, there is a lack of research as to whether VitD supplementation can improve exercise performance through decreasing limiting factors such as muscular fatigue and damage in athletes who have sufficient levels of VitD. Thus, future studies that combine high dose VitD supplementation and exercise in healthy models should be considered.

In the current study, it was observed that the control animals fed the high VitD diet elicited greater forces per CSA when compared to the low and medium diets (Figure 1D). Furthermore, supplementation with the medium and high VitD diets delayed fatigue during the first two minutes of fatigue in non-dystrophic EDL muscles. These findings suggest that increased VitD (from a non-depleted state) may aid in conserving force output in slow-type I muscle fibers and aids in improving fatigue and recovery in the highly fatigable type-II fibers. However, further work is required to investigate this.

\section{Conclusions}

In conclusion, VitD supplementation did not appear to have any beneficial effect on the contractile properties or regenerative capacity of dystrophic skeletal muscle in the $m d x$ mouse. Following contractile testing, it was observed that an increase in VitD intake did not lead to increased force output in dystrophic compared to non-dystrophic animals. Further to this, fatigability of dystrophic muscles and their ability to recover from fatigue was also not affected by VitD supplementation. Beginning supplementation earlier, or from a VitD deficient state, may more definitively answer whether there really is no effect. Although differences were not observed as a result of VitD supplementation in the $m d x$ animals, several differences were observed in the maintenance of force during fatigue and recovery in control animals. These findings could suggest that VitD supplementation may be beneficial from an athletic point of view to increase muscle performance when applied in a VitD replete state, thus providing a further avenue for future research.

Author Contributions: Conceptualization, E.D.H., E.R. and A.H.; Formal analysis, D.A.D., N.A., C.A.T. and A.H.; Investigation, D.A.D., N.A. and C.A.T.; Project administration, A.H.; Supervision, E.D.H., E.R. and A.H.; Visualization, D.A.D. and N.A.; Writing-original draft, D.A.D. and N.A.; Writing-review \& editing, E.D.H., C.A.T., E.R. and A.H.

Funding: This research received no external funding. 
Conflicts of Interest: The authors declare no conflict of interest.

\section{References}

1. Perez-Lopez, F.R. Vitamin D: The secosteroid hormone and human reproduction. Gynecol. Endocrinol. 2007, 23, 13-24. [CrossRef] [PubMed]

2. Parker-Autry, C.Y.; Burgio, K.L.; Richter, H.E. Vitamin D status: A review with implications for the pelvic floor. Int. Urogynecology J. 2012, 23, 1517-1526. [CrossRef]

3. Christakos, S.; Dhawan, P.; Verstuyf, A.; Verlinden, L.; Carmeliet, G. Vitamin D: Metabolism, Molecular Mechanism of Action, and Pleiotropic Effects. Physiol. Rev. 2015, 96, 365-408. [CrossRef] [PubMed]

4. Hamilton, B. Vitamin D and human skeletal muscle. Scand. J. Med. E Sci. sports 2010, 20, 182-190. [CrossRef]

5. Stratos, I.; Li, Z.; Herlyn, P.; Rotter, R.; Behrendt, A.-K.; Mittlmeier, T.; Vollmar, B. Vitamin D Increases Cellular Turnover and Functionally Restores the Skeletal Muscle after Crush Injury in Rats. Am. J. Pathol. 2013, 182, 895-904. [CrossRef]

6. Owens, D.J.; Sharples, A.P.; Polydorou, I.; Alwan, N.; Donovan, T.; Tang, J.; Fraser, W.D.; Cooper, R.G.; Morton, J.P.; Stewart, C.; et al. A systems-based investigation into vitamin D and skeletal muscle repair, regeneration, and hypertrophy. Am. J. Physiol. Endocrinol. Metab. 2015, 309, E1019-E1031. [CrossRef] [PubMed]

7. Girgis, C.M.; Cha, K.M.; Houweling, P.J.; Rao, R.; Mokbel, N.; Lin, M.; Clifton-Bligh, R.J.; Gunton, J.E. Vitamin D Receptor Ablation and Vitamin D Deficiency Result in Reduced Grip Strength, Altered Muscle Fibers, and Increased Myostatin in Mice. Calcif. Tissue Int. 2015, 97, 602-610. [CrossRef]

8. Drittanti, L.; de Boland, A.R.; Boland, R. Stimulation of calmodulin synthesis in proliferating myoblasts by 1,25-dihydroxy-vitamin D3. Mol. Cell. Endocrinol. 1990, 74, 143-153. [CrossRef]

9. Santillán, G.; Katz, S.; Vazquez, G.; Boland, R.L. TRPC3-like protein and Vitamin D receptor mediate $1 \alpha, 25(\mathrm{OH}) 2 \mathrm{D} 3-i n d u c e d$ SOC influx in muscle cells. Int. J. Biochem. E Cell Biol. 2004, 36, 1910-1918. [CrossRef]

10. Fairclough, R.J.; Bareja, A.; Davies, K.E. Progress in therapy for Duchenne muscular dystrophy. Exp. Physiol. 2011, 96, 1101-1113. [CrossRef]

11. Bushby, K.M. Genetic and clinical correlations of Xp21 muscular dystrophy. J. Inherit. Metab. Dis. 1992, 15, 551-564. [CrossRef]

12. Bianchi, M.L.; Morandi, L.; Andreucci, E.; Vai, S.; Frasunkiewicz, J.; Cottafava, R. Low bone density and bone metabolism alterations in Duchenne muscular dystrophy: response to calcium and vitamin D treatment. Osteoporos. Int. 2011, 22, 529-539. [CrossRef] [PubMed]

13. Bellayou, H.; Hamzi, K.; Rafai, M.A.; Karkouri, M.; Slassi, I.; Azeddoug, H.; Nadifi, S. Duchenne and Becker Muscular Dystrophy: Contribution of a Molecular and Immunohistochemical Analysis in Diagnosis in Morocco. J. Biomed. Biotechnol. 2009, 2009, 5. [CrossRef] [PubMed]

14. Yilmaz, O.; Karaduman, A.; Topaloglu, H. Prednisolone therapy in Duchenne muscular dystrophy prolongs ambulation and prevents scoliosis. Eur. J. Neurol. 2004, 11, 541-544. [CrossRef]

15. Lynch, G.S.; Hinkle, R.T.; Chamberlain, J.S.; Brooks, S.V.; Faulkner, J.A. Force and power output of fast and slow skeletal muscles from mdx mice 6-28 months old. J. Physiol. 2001, 535, 591-600. [CrossRef] [PubMed]

16. Sato, Y.; Iwamoto, J.; Kanoko, T.; Satoh, K. Low-dose vitamin D prevents muscular atrophy and reduces falls and hip fractures in women after stroke: a randomized controlled trial. Cerebrovasc. Dis. 2005, 20, 187-192. [CrossRef] [PubMed]

17. Zhu, K.; Austin, N.; Devine, A.; Bruce, D.; Prince, R.L. A randomized controlled trial of the effects of vitamin $\mathrm{D}$ on muscle strength and mobility in older women with vitamin D insufficiency. J. Am. Geriatr. Soc. 2010, 58, 2063-2068. [CrossRef]

18. Agostini, D.; Zeppa Donati, S.; Lucertini, F.; Annibalini, G.; Gervasi, M.; Ferri Marini, C.; Piccoli, G.; Stocchi, V.; Barbieri, E.; Sestili, P. Muscle and Bone Health in Postmenopausal Women: Role of Protein and Vitamin D Supplementation Combined with Exercise Training. Nutrients 2018, 10. [CrossRef]

19. Van Veldhuizen, P.J.; Taylor, S.A.; Williamson, S.; Drees, B.M. Treatment of Vitamin D Deficiency in Patients with Metastatic Prostate Cancer May Improve Bone Pain and Muscle Strength. J. Urology 2000, 163, 187-190. [CrossRef]

20. Dangain, J.; Vrbova, G. Muscle development in mdx mutant mice. Muscle \& Nerve 1984, 7, 700-704. [CrossRef] 
21. Spurney, C.F.; Gordish-Dressman, H.; Guerron, A.D.; Sali, A.; Pandey, G.S.; Rawat, R.; Van Der Meulen, J.H.; Cha, H.J.; Pistilli, E.E.; Partridge, T.A.; et al. Preclinical drug trials in the mdx mouse: Assessment of reliable and sensitive outcome measures. Muscle $\mathcal{E}$ Nerve 2009, 39, 591-602. [CrossRef]

22. Bulfield, G.; Siller, W.G.; Wight, P.A.; Moore, K.J. X chromosome-linked muscular dystrophy (mdx) in the mouse. Proc. Nat. Academy Sci. USA 1984, 81, 1189-1192. [CrossRef]

23. Allen, D.G.; Gervasio, O.L.; Yeung, E.W.; Whitehead, N.P. Calcium and the damage pathways in muscular dystrophy. Can. J. Physiol. Pharmacol. 2010, 88, 83-91. [CrossRef] [PubMed]

24. Pertille, A.; de Carvalho, C.L.T.; Matsumura, C.Y.; Neto, H.S.; Marques, M.J. Calcium-binding proteins in skeletal muscles of the mdx mice: potential role in the pathogenesis of Duchenne muscular dystrophy. Int. J. Exp. Pathol. 2010, 91, 63-71. [CrossRef]

25. Hibaoui, Y.; Reutenauer-Patte, J.; Patthey-Vuadens, O.; Ruegg, U.T.; Dorchies, O.M. Melatonin improves muscle function of the dystrophic mdx5Cv mouse, a model for Duchenne muscular dystrophy. J. Pineal Res. 2011, 51, 163-171. [CrossRef]

26. Harisseh, R.; Chatelier, A.; Magaud, C.; Déliot, N.; Constantin, B. Involvement of TRPV2 and SOCE in calcium influx disorder in DMD primary human myotubes with a specific contribution of $\alpha 1$-syntrophin and PLC/PKC in SOCE regulation. Am. J. Physiol. Cell Physiol. 2013, 304, C881-C894. [CrossRef]

27. Radley-Crabb, H.G.; Marini, J.C.; Sosa, H.A.; Castillo, L.I.; Grounds, M.D.; Fiorotto, M.L. Dystropathology increases energy expenditure and protein turnover in the $\mathrm{mdx}$ mouse model of duchenne muscular dystrophy. PloS One 2014, 9, e89277. [CrossRef] [PubMed]

28. Fontana, S.; Schillaci, O.; Frinchi, M.; Giallombardo, M.; Morici, G.; Di Liberto, V.; Alessandro, R.; De Leo, G.; Perciavalle, V.; Belluardo, N.; et al. Reduction in mdx mouse muscle degeneration by low-intensity endurance exercise: A proteomic analysis in quadriceps muscle of exercised compared with sedentary mdx mice. Biosci. Rep. 2015, 35, e00213. [CrossRef]

29. Chan, S.; Head, S.I. The role of branched fibres in the pathogenesis of Duchenne muscular dystrophy. Exp. Physiol. 2011, 96, 564-571. [CrossRef] [PubMed]

30. Brooks, S.V.; Faulkner, J.A. Contractile properties of skeletal muscles from young, adult and aged mice. J. Physiol. 1988, 404, 71-82. [CrossRef]

31. Close, R.I. Dynamic properties of mammalian skeletal muscles. Physiol. Rev. 1972, 52, 129-197. [CrossRef]

32. Petrof, B.J.; Shrager, J.B.; Stedman, H.H.; Kelly, A.M.; Sweeney, H.L. Dystrophin protects the sarcolemma from stresses developed during muscle contraction. P Proc. Nat. Academy Sci. USA 1993, 90, 3710-3714. [CrossRef]

33. Call, J.A.; Warren, G.L.; Verma, M.; Lowe, D.A. Acute failure of action potential conduction in mdx muscle reveals new mechanism of contraction-induced force loss. J. Physiol. 2013, 591, 3765-3776. [CrossRef]

34. Call, J.A.; Eckhoff, M.D.; Baltgalvis, K.A.; Warren, G.L.; Lowe, D.A. Adaptive strength gains in dystrophic muscle exposed to repeated bouts of eccentric contraction. J. Appl. Physiol. 2011, 111, 1768-1777. [CrossRef]

35. Stapleton, D.I.; Lau, X.; Flores, M.; Trieu, J.; Gehrig, S.M.; Chee, A.; Naim, T.; Lynch, G.S.; Koopman, R. Dysfunctional muscle and liver glycogen metabolism in mdx dystrophic mice. PloS One 2014, 9, e91514. [CrossRef]

36. Hayes, A.; Williams, D.A. Contractile function and low-intensity exercise effects of old dystrophic (mdx) mice. Am. J. Physiol. 1998, 274, C1138-C1144. [CrossRef]

37. Hayes, A.; Williams, D.A. Beneficial effects of voluntary wheel running on the properties of dystrophic mouse muscle. J. appl. Physiol. 1996, 80, 670-679. [CrossRef]

38. Webster, C.; Silberstein, L.; Hays, A.P.; Blau, H.M. Fast muscle fibers are preferentially affected in Duchenne muscular dystrophy. Cell 1988, 52, 503-513. [CrossRef]

39. Pedemonte, M.; Sandri, C.; Schiaffino, S.; Minetti, C. Early Decrease of IIx Myosin Heavy Chain Transcripts in Duchenne Muscular Dystrophy. Biochem. Biophys. Res. Commun. 1999, 255, 466-469. [CrossRef]

40. Fink, R.H.; Stephenson, D.G.; Williams, D.A. Calcium and strontium activation of single skinned muscle fibres of normal and dystrophic mice. J. Physiol. 1986, 373, 513-525. [CrossRef]

41. Williams, D.A.; Head, S.I.; Bakker, A.J.; Stephenson, D.G. Resting calcium concentrations in isolated skeletal muscle fibres of dystrophic mice. J. Physiol. 1990, 428, 243-256. [CrossRef]

42. Fink, R.H.; Stephenson, D.G.; Williams, D.A. Physiological properties of skinned fibres from normal and dystrophic (Duchenne) human muscle activated by $\mathrm{Ca}^{2+}$ and $\mathrm{Sr}^{2+}$. J. Physiol. 1990, 420, 337-353. [CrossRef] 
43. Tanihata, J.; Nagata, T.; Saito, T.; Ito, N.; Aoki, Y.; Nakamura, A.; Takeda, S. GP 85: Truncated dystrophin with exon 45-55 deletion induced muscle atrophy and fiber type change through the hyper-nitrosylation of the ryanodine receptor type- 1 and constant release of $\mathrm{Ca}^{2+}$ to the cytosol. Neuromuscul. Disord. 2014, 24, 820. [CrossRef]

44. Selsby, J.T.; Morine, K.J.; Pendrak, K.; Barton, E.R.; Sweeney, H.L. Rescue of Dystrophic Skeletal Muscle by PGC-1 $\alpha$ Involves a Fast to Slow Fiber Type Shift in the mdx Mouse. PloS One 2012, 7, e30063. [CrossRef]

45. Garcia, L.A.; Ferrini, M.G.; Norris, K.C.; Artaza, J.N. 1,25(OH $)_{2}$ vitamin $\mathrm{D}_{3}$ enhances myogenic differentiation by modulating the expression of key angiogenic growth factors and angiogenic inhibitors in $\mathrm{C}_{2} \mathrm{C}_{12}$ skeletal muscle cells. J. Steroid Biochem. Mol. Biol. 2013, 133, 1-11. [CrossRef]

46. Dahlquist, D.T.; Dieter, B.P.; Koehle, M.S. Plausible ergogenic effects of vitamin D on athletic performance and recovery. J. Int. Soc. Sports Nutri. 2015, 12,1-12. [CrossRef]

47. Ward, K.A.; Das, G.; Berry, J.L.; Roberts, S.A.; Rawer, R.; Adams, J.E.; Mughal, Z. Vitamin D Status and Muscle Function in Post-Menarchal Adolescent Girls. J. Clin. Endocrinol. E Metab. 2009, 94, 559-563. [CrossRef]

48. Wyon, M.A.; Koutedakis, Y.; Wolman, R.; Nevill, A.M.; Allen, N. The influence of winter vitamin D supplementation on muscle function and injury occurrence in elite ballet dancers: A controlled study. J. Sci. Med. Sport 2014, 17, 8-12. [CrossRef]

49. Close, G.L.; Russell, J.; Cobley, J.N.; Owens, D.J.; Wilson, G.; Gregson, W.; Fraser, W.D.; Morton, J.P. Assessment of vitamin D concentration in non-supplemented professional athletes and healthy adults during the winter months in the UK: Implications for skeletal muscle function. J. Sports Sci. 2013, 31, 344-353. [CrossRef]

50. Barker, T.; Martins, T.B.; Hill, H.R.; Kjeldsberg, C.R.; Dixon, B.M.; Schneider, E.D.; Henriksen, V.T.; Weaver, L.K. Circulating pro-inflammatory cytokines are elevated and peak power output correlates with 25-hydroxyvitamin D in vitamin D insufficient adults. Eur. J. Appl. Physiol. 2013, 113, 1523-1534. [CrossRef]

51. Barker, T.; Henriksen, V.T.; Martins, T.B.; Hill, H.R.; Kjeldsberg, C.R.; Schneider, E.D.; Dixon, B.M.; Weaver, L.K. Higher serum 25-hydroxyvitamin D concentrations associate with a faster recovery of skeletal muscle strength after muscular injury. Nutrients 2013, 5, 1253-1275. [CrossRef] [PubMed]

52. Mowry, D.A.; Costello, M.M.; Heelan, K.A. Association among cardiorespiratory fitness, body fat, and bone marker measurements in healthy young females. J. Am. Osteopath. Assoc. 2009, 109, 534-539. [PubMed]

53. Ardestani, A.; Parker, B.; Mathur, S.; Clarkson, P.; Pescatello, L.S.; Hoffman, H.; Polk, D.; Thompson, P.D. Relation of Vitamin D Level to Maximal Oxygen Uptake in Adults. Am. J. Cardiol. 2011, 107, 1246-1249. [CrossRef] [PubMed]

54. Weltman, A.; Snead, D.; Stein, P.; Seip, R.; Schurrer, R.; Rutt, R.; Weltman, J. Reliability and validity of a continuous incremental treadmill protocol for the determination of lactate threshold, fixed blood lactate concentrations, and $\mathrm{VO}_{2 \max }$. Int. J. Sports Med. 1990, 11, 26-32. [CrossRef]

(C) 2019 by the authors. Licensee MDPI, Basel, Switzerland. This article is an open access article distributed under the terms and conditions of the Creative Commons Attribution (CC BY) license (http://creativecommons.org/licenses/by/4.0/). 